\title{
Long-term effects of best management practices on crop yield and nitrogen surplus
}

\author{
Laura Zavattaro, ${ }^{1}$ Chiara Costamagna, ${ }^{1}$ Carlo Grignani, ${ }^{1}$ Luca Bechini, ${ }^{2}$ Adelheid Spiegel, ${ }^{3}$ \\ Taru Lehtinen, ${ }^{3}$ Gema Guzmán, ${ }^{4}$ Janine Krüger, ${ }^{5}$ Tommy D'Hose, ${ }^{6}$ Alicja Pecio, ${ }^{7}$ \\ Frits K. van Evert, ${ }^{8}$ Hein F.M. ten Berge ${ }^{8}$ \\ 1Department of Agricultural Forest and Food Sciences, University of Torino, Italy; \\ 2Department of Agricultural and Environmental Sciences, University of Milano, Italy; \\ ${ }^{3}$ Austrian Agency for Health and Food Safety, Vienna, Austria; ${ }^{4}$ Department of Agronomy, \\ University of Córdoba, Córdoba, Spain; ${ }^{5}$ Centre of Biodiversity and Sustainable Land Use, \\ Grossbeeren, Germany; ${ }^{6}$ Institute for Agricultural and Fisheries Research, Merelbeke, \\ Belgium; ${ }^{7}$ Institute of Soil Science and Plant Cultivation, Puławi, Poland; ${ }^{8}$ DLO \\ Foundation, Wageningen UR, The Netherlands
}

\begin{abstract}
Inherent in the concept of good agricultural practice (BMP) is that it improves resource use efficiency, mitigates environmental impact or increases farm profitability. However, it is usually impossible to achieve all the objectives, and trade-offs need to be accepted, such as a reduction in productivity together with a reduction in costs or an increase of soil organic matter. A European FP7 project, Catch-C (http://www.catch-c.eu) analyses the effects that different management practices have on productivity, mitigation of climate change and chemical, physical and biological soil fertility, based on simple indicators. Such indicators were collected from international literature,
\end{abstract}

Correspondence: Laura Zavattaro, Department of Agricultural Forest and Food Sciences (DISAFA), Università degli Studi di Torino, Largo Braccini 2, 10095 Grugliasco (TO), Italy.

Tel.: +39.011.6708786 - Fax: +39.011 .6708798 .

E-mail: laura.zavattaro@unito.it

Key words: best management practice, climate change, cropping system, nitrogen, yield.

Conference presentation: SIA XLIII Congress, Pisa, 2014.

Funding: this study was part of the European CATCH-C project that is funded within the $7^{\text {th }}$ Framework Programme (Grant Agreement No. 289782).

Received for publication: 18 December 2014.

Revision received: 30 January 2015.

Accepted for publication: 31 January 2015.

(C) Copyright L. Zavattaro et al., 2015

Licensee PAGEPress, Italy

Italian Journal of Agronomy 2015; 10:643

doi:10.4081/ija.2015.643

This article is distributed under the terms of the Creative Commons Attribution Noncommercial License (by-nc 3.0) which permits any noncommercial use, distribution, and reproduction in any medium, provided the original author(s) and source are credited. national scientific or technical journals, or grey literature that dealt with long-term field trials in Europe. We collected and analysed data from more than 350 experiments.

This paper presents the overall results of the effects of a series of BMP have on crop productivity, soil nitrogen (N) uptake, $\mathrm{N}$ use efficiency end $\mathrm{N}$ balance. Important interactions with soil and climate types, crop and duration of the experiment were noticed for most BMPs. Rotations, also including double cropping, were among practices with more positive effects of productivity and $\mathrm{N}$ indicators. A slight reduction of yield counteracted benefits to soil quality and to climate change mitigation of minimum and no tillage, and of organic fertilisers.

\section{Introduction}

Soil management practices such as crop rotation, adoption of cover crops and green manuring, crop residue incorporation and substitution of mineral with organic fertilisers may maintain soil fertility and ensure adequate crop productivity and efficient use of resources.

The effects of agricultural practices can only be assessed properly in long-term experiments (LTEs), where small changes can accumulate over the years until they become detectable, and interaction with meteorological variability can be assessed (Johnston, 1994).

In the context of the European project Catch-C (http://www.catchc.eu), we performed a review of European LTEs on arable crops to verify the hypothesis that the above mentioned practices are not only effective in improving the soil quality, but also in maintaining high yields and quality. Here, the results related to crop productivity and nitrogen (N) use are presented.

\section{Materials and methods}

We analysed multi-year averages of crop yields, $\mathrm{N}$ uptake and field $\mathrm{N}$ surplus (difference between $\mathrm{N}$ supply and $\mathrm{N}$ removal) from 106 LTEs across Europe. Our literature review included scientific and technical papers, and grey literature, both in English and in national languages, yielding a total of 115 papers.

Agricultural practices considered were crop rotation; catch/cover 
crops (either harvested or incorporated in the soil as green manure); no-tillage and minimum tillage; organic fertilisation with compost, farmyard manure, or bovine slurry; and crop residue incorporation into the soil.

Yields obtained using each practice were divided by those obtained when the practice was not adopted (i.e. reference treatment): rotation $v s$ monoculture, catch crops or green manure $v s$ bare soil; no-tillage and minimum tillage $v s$ conventional tillage; organic fertilisation $v s$ mineral fertilisation at the same nitrogen input; crop residue incorporation $v s$ removal. The comparisons were made by ensuring that all factors different other than the one tested were equal in the two treatments under comparison (e.g. two tillage treatments were compared within the same rotation). The obtained indicator is called the response ratio (RR), and it is greater than one when the practice increases yield. Nitrogen uptake and $\mathrm{N}$ use efficiency (NUE) were also analysed using $\mathrm{RR}$, while $\mathrm{N}$ surplus was examined using the difference between the practice and reference treatment (DIFF). A negative DIFF indicates a reduction in surplus when the practice is adopted.

A one-sample t-test (2 tails) was used to identify which RR means were significantly different from 1 , and which DIFF means were significantly different from $0(\mathrm{P}<0.05)$.

A multiple linear model was performed using climate type (Metzger et al., 2005), soil type and duration of practice (4 levels each), and crop type (12 levels) as nominal factors, to evaluate which conditions mostly affected the performance of each practice (Zavattaro et al., 2014).

\section{Results}

Results are reported in Figure 1. Further details can be found in Zavattaro et al., 2014.

In more than $80 \%$ of the cases, the yield of a crop grown in a rotation was larger than the yield of the same crop grown in a monoculture, and the average increase in yield was $5 \%$. The largest differences were found in the Western European climate, on sand or loam soils, with wheat or grain maize, and in long-lasting experiments (10-20 years). Conversely, legume or grass leys and minor small grain cereals (such as rye or triticale), and clayey soils represented unfavourable conditions for a rotation. However, while the productivity of a specific crop could be increased in a rotation, the dry matter production of the entire rotation was generally lower than that of the single crop grown in monoculture. Crop $\mathrm{N}$ uptake was also generally increased and $\mathrm{N}$ surplus was reduced in a rotation compared to a monoculture.

In $60 \%$ of the cases, the use of a harvested leguminous or non-leguminous catch/cover crop resulted in a yield increase of the main crop. Best results were obtained in Eastern Europe, in soils other than silty, crops such as barley, maize or minor cereals, and in long-lasting experiments. Nitrogen uptake was also increased in $80 \%$ of cases, and consequently $\mathrm{N}$ surplus was reduced. Little or no overall effect of incorporated green manure on yield and $\mathrm{N}$ uptake was observed, in all pedo-climatic conditions explored. The $\mathrm{N}$ uptake and $\mathrm{N}$ surplus of the main crop was reported only in two cases in northern Europe, with opposite trends: positive for barley, negative for wheat. None of the factors considered in the multiple linear model was significant.

No-tillage has been widely studied in Europe, especially in southern and western countries. Most of LTEs were started in the ' 80 s, and published data are therefore referred to several years of application. Wheat and barley are the most frequent tested crops. On average we observed a yield reduction of $4 \%$ in no-tillage compared to conventional tillage, although the change ranged from $-32 \%$ to $+31 \%$, following a normal distribution. Silty soils performed the best. Nitrogen uptake was lower in $73 \%$ of cases, resulting in an average non-significant reduction by
$5 \%$. Nitrogen surplus was enhanced up to $+43 \mathrm{~kg} \mathrm{~N} \mathrm{ha}^{-1}$, or reduced up to $-88 \mathrm{~kg} \mathrm{~N}$ ha ${ }^{-1}$, depending on the crop $\mathrm{N}$ removal. The RR of NUE showed an overall average tendency to increase by about $5 \%$.

We classified as minimum tillage a variety of experimental treatments carried out with heterogeneous machinery. What all management practices had in common was that they did not imply an inversion of the soil and that tillage was performed at a shallower depth than normally adopted in ploughing in the same area. We observed RR of 0.97 (significantly different from 1) between yields under minimum and conventional tillage; however, it ranged from +52 to $-46 \%$, and $65 \%$ of the values were smaller than 1 . Most of cases lay between -10 and $+5 \%$. Nitrogen uptake and efficiency were more sensitive than yield: they were significantly reduced in $92 \%$ of cases and by $9 \%$ on average, thus evidencing that $\mathrm{N}$ availability was reduced with minimum tillage. Nitrogen surplus was consequently increased by $13 \mathrm{~kg} \mathrm{~N} \mathrm{ha}^{-1}$ on average. None of the factors considered resulted to affect the performance of this technique on yield, whereas $\mathrm{N}$ uptake and $\mathrm{N}$ surplus were significantly affected by climate (in particular, $\mathrm{N}$ uptake was increased and $\mathrm{N}$ surplus was reduced in Western Europe Atlantic climate).

All kinds of composts (plant-based, biowaste or sludge materials) were pooled in this analysis, for a total of 21 experiments, mainly located in Central Europe. When compared to a similar $\mathrm{N}$ fertilisation level supplied using mineral fertilisers, compost additions showed a good supplying capacity of nutrients, as yield RR had a mean of 0.95 (not significantly different from 1 ). More than $70 \%$ of cases lay in the range +6 to $-6 \%$; in one case in Scandinavia, with maize on a clay soil, the performance was remarkably high (+67\% of yield). Best results with compost were obtained when vegetables (leeks, Brussels sprouts) and peas were cropped, while grain maize and barley yield was notably depressed. As several authors report (Alluvione et al., 2013), compost can release nutrients slowly and immobilisation can occur in the first years of supply. Therefore, it is not surprising that good results with this fertilisation practice were observed only after some years of repeated additions ( $>5$ years).

The 60 experiments on farmyard manure used for this study were mainly located in Eastern European (Pannonian) climatic conditions and medium or coarse-textured soils. Especially, long-term experiments, which lasted for more than 20 years, were represented. On average, a significant reduction in yield by $6 \%$ was observed. The variability around the mean was notable; $52 \%$ of RRs were smaller than 1 . Results obtained in northern Europe on fodder maize were extremely positive, although the absolute yield was rather low $\left(<5.5 \mathrm{t} \mathrm{ha}^{-1}\right.$ of aboveground dry matter in the manured plots). Conversely, eight cases in Western Europe with Atlantic climate showed a reduction in marketable production. Coarse-textured soils, where mineralisation is enhanced, created more favourable condition for manured treatments. All tested crops responded to manure application in a similar way, according to the statistical test. However, a tendency to benefit more of the $\mathrm{N}$ mineralisation of organic fertilisers was observed in summer crops, probably because they can better exploit $\mathrm{N}$ released from mineralisation of manure, if compared with crops whose maximum requirements are asynchronous with the organic fertiliser mineralisation curve.

Bovine slurry was tested in 37 experiments that were located mainly in Eastern and Southern Europe. Most experiments lasted for more than 10 years. Tested crops were mainly forages, and coarse-textured soils were the most represented. In these conditions, a rapid mineralisation led to a fast release of $\mathrm{N}$ in the soil, similar to that of mineral fertilisers (RR not significantly different from 1). Values of the yield RR of slurry showed a normal distribution around a mean of 0.98 , ranging from 0.52 to 1.58 , and greater than 1 in $46 \%$ of cases. Therefore, bovine slurry performed even better than solid manure. On the other hand, $\mathrm{N}$ uptake ( $n=11$ ) was $8 \%$ lower (significantly different from 1 ) than in treatments that received mineral fertilisers. 
Generally, the performance of all organic fertilisers depended on the soil type (best results in coarse-textured soils), climate (the colder, the better) and duration of practice (better results in experiments lasting for more than 5-10 years). In some of the experiments, crop residues acted as a source of nutrients or of stable organic matter, which improved soil physical, chemical, biological and hydraulic characteristics. Incorporation of residues caused an increase in soil organic carbon content of about 7\% in the same dataset (Lehtinen et al., 2014). However, in other cases straw immobilised $\mathrm{N}$ or caused technical diffi- culties at sowing. The overall mean RR of incorporating residues was significantly different from 1 and negative (-7\%), although $49 \%$ of the values were greater than 1 . The maximum value was $+16 \%$. Minimum values $(\mathrm{RR}<0.55)$ came from two experiments in Slovenia. Residue incorporation was detrimental to crop yield especially in badly structured silty soils, in all crops. Nitrogen indicators were too limited to be representative and were recorded only in continental climate. A slight reduction in $\mathrm{N}$ uptake was observed; conversely, the overall $\mathrm{N}$ surplus was decreased and NUE was increased by $36 \%$.
A

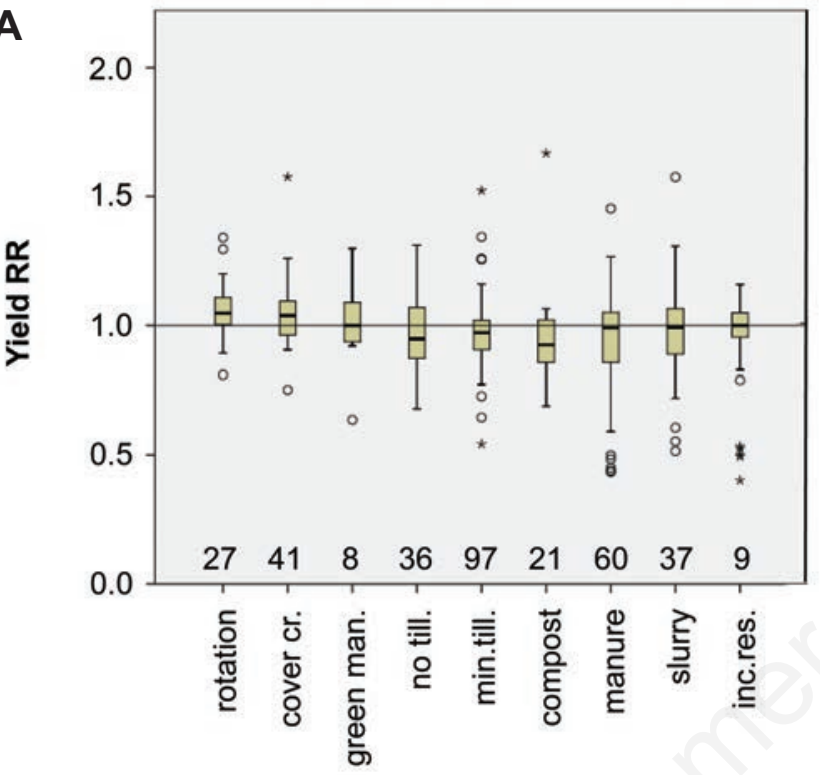

B

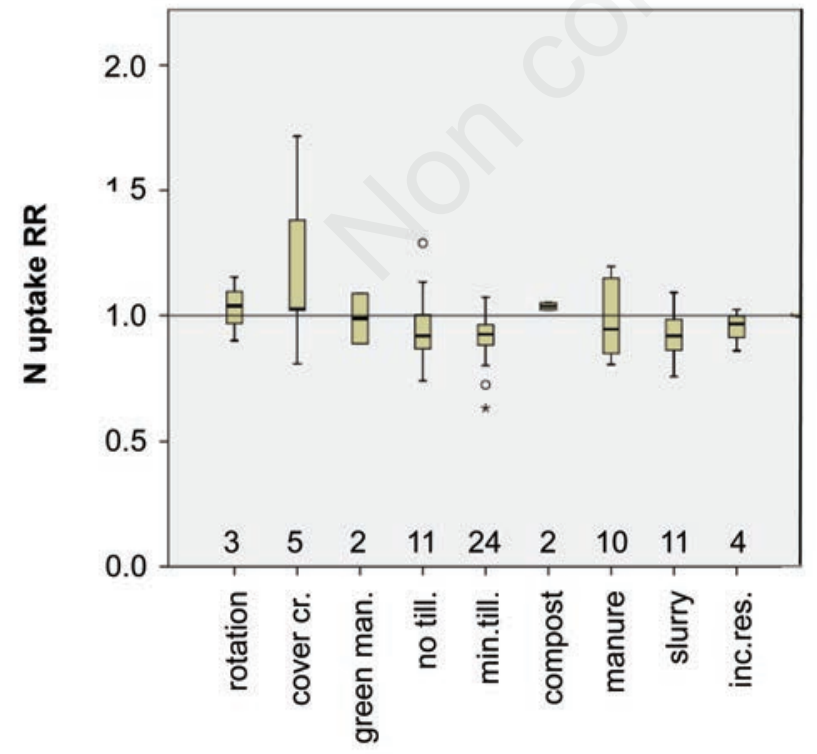

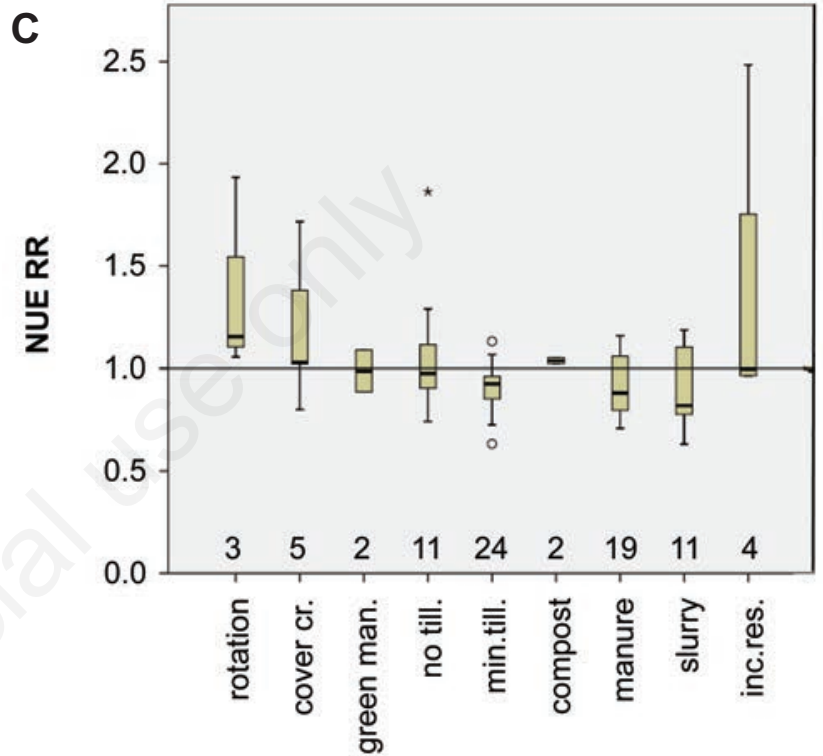

D

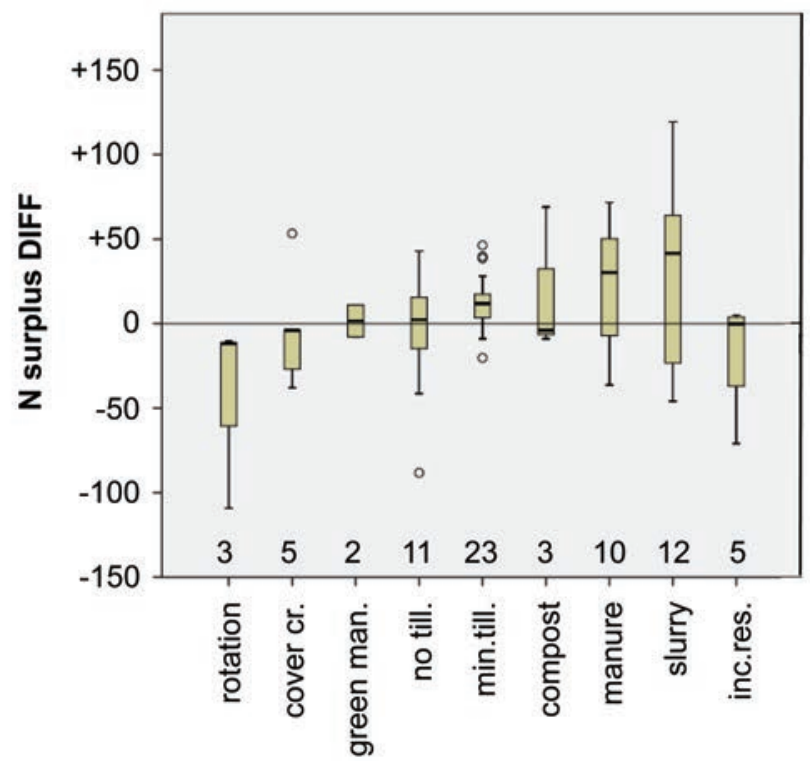

Figure 1. Boxplot graphs of: A) yield response ratio (RR); B) nitrogen (N) uptake RR; C) $N$ use efficiency (NUE) RR and D) N surplus difference between practice and reference treatment (DIFF) obtained adopting improved management practices compared to standard practices. Numbers indicate the number of studies considered for each practice. Cover cr, catch/cover crops; green man, green manure; no till., no tillage; min. till., minimum tillage; inc. res., incorporation of crop residues. 


\section{Conclusions}

The indicator-based evaluation of agricultural management practices showed positive and negative effects. Productivity was enhanced when adopting rotation and cover crops. A slight reduction of yield counteracted the benefits to soil quality and to climate change mitigation of minimum and no tillage, and of organic fertilisers. The most important single factor influencing the effect of management practices was the climate type.

\section{References}

Alluvione F, Fiorentino N, Bertora C, Zavattaro L, Fagnano M, Quaglietta Chiarandà F, Grignani C, 2013. Short-term crop and soil response to C-friendly strategies in two contrasting environments. Eur. J. Agron. 45:114-23.

Johnston AE, 1994. The Rothamsted classical experiments. In: Leigh R.A. and Johnston A.E. (eds.), Long-term experiments in agricultural and ecological sciences. Proc. Conf. Celebrate the $150^{\text {th }}$ Anniversary of Rothamsted Experimental Station, 14-17 July 1993. CAB International, Wallingford, UK, pp 9-37.

Lehtinen T, Schlatter N, Baumgarten A, Bechini L, Krüger J, Grignani C, Zavattaro L, Costamagna C, Spiegel H, 2014. Effect of crop residue incorporation on soil organic carbon and greenhouse gas emissions in European agricultural soils. Soil Use Manage. 30:524-38.

Metzger MJ, Bunce RGH, Jongman RHG, Mucher CA, Watkins JW, 2005. A climatic stratification of the environment of Europe. Global Ecol. Biogeogr. 14:549-63.

Zavattaro L, Costamagna C, Grignani C, Bechini L, 2014. Impacts of soil management on productivity (Project deliverable No. D3.324), CATCH-C project deliverable. Wageningen, The Netherlands. Available from: http://www.catch-c.eu/deliverables/ 